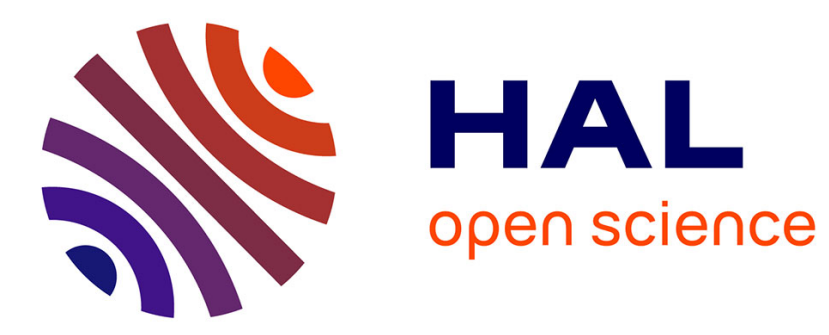

\title{
High Damping Capacity Coatings for Surface Vibration Control
}

\author{
A. Karimi, P. Giauque, J. Martin, G. Barbezat, A. Salito
}

\section{To cite this version:}

A. Karimi, P. Giauque, J. Martin, G. Barbezat, A. Salito. High Damping Capacity Coatings for Surface Vibration Control. Journal de Physique IV Proceedings, 1996, 06 (C8), pp.C8-779-C8-782. 10.1051/jp4:19968166 . jpa-00254601

\section{HAL Id: jpa-00254601 https://hal.science/jpa-00254601}

Submitted on 1 Jan 1996

HAL is a multi-disciplinary open access archive for the deposit and dissemination of scientific research documents, whether they are published or not. The documents may come from teaching and research institutions in France or abroad, or from public or private research centers.
L'archive ouverte pluridisciplinaire HAL, est destinée au dépôt et à la diffusion de documents scientifiques de niveau recherche, publiés ou non, émanant des établissements d'enseignement et de recherche français ou étrangers, des laboratoires publics ou privés. 


\title{
High Damping Capacity Coatings for Surface Vibration Control
}

\author{
A. Karimi, P.H. Giauque, J.L. Martin, G. Barbezat* and A. Salito* \\ Ecole Polytechnique Fédérale de Lausanne, Département de Physique, Institut de Génie Atomique, \\ 1015 Lausanne, Switzerland \\ * Sulzer Metco AG, 5610 Wohlen, Switzerland
}

\begin{abstract}
The damping capacity $Q^{-1}$ of a number of $\mathrm{Fe}-16 \% \mathrm{Cr}$ alloys containing $(0-6) \% \mathrm{Al}$ and $(0-4) \% \mathrm{Mo}$ has been investigated and compared to that of thermally sprayed coatings. The magnetomechanical hysteresis loss was determined using a cantilever method and based on the modal analysis technique of flat beam samples. Heat treatments usually enhanced the loss capability, but further annealing destroyed it drastically. The plasma sprayed coatings was found to require more annealing to exhibit comparable damping capacity to cast alloys of the same chemical composition. The variation of $Q^{-1}$ versus vibration amplitude first increased rapidly, passed through a maximum around $\varepsilon=10^{-4}$ and then declined relatively slowly to its initial values. The structure of magnetic domains were observed using the magneto-optical Kerr effect and their modification following to an applied stress or magnetic field was associated with different values of the damping capacity. The irreversible movement of domain walls upon application of an external stress occurred suddenly and abruptly between two pinned positions.
\end{abstract}

\section{INTRODUCTION}

The magnetoelastic coupling in ferromagnetic materials has been highlighted for many years to result in an important source of internal friction and thereby to provide a high damping capacity [1-3]. Several experimental works have been dealt with this effect in order to develop high damping alloys for reduction of noise and vibration damages in industrial components. Among the magnetomechanical damping materials, the high chromium ferritic steels have been particularly considered because of their elevated mechanical properties and good corrosion resistance. Masumoto et al. [4] studied the damping capacity of a number of iron-chromium alloys in relation with their chemical composition and heat treatment conditions. The values of $\mathrm{Q}^{-1}$ increased by high temperature annealing of samples, and showed a maximum versus strain amplitude around $\gamma_{m}=10^{-4}$. Following the annealing of samples, the alloys with lower content of chromium resulted in the formation of non-ferromagnetic $\gamma$ phase, whereas higher content of chromium led to the appearance of $\sigma$ precipitate, both of them undesirable for high damping capacity. Amano et al [5] investigated the magnetic properties and the loss capability of $\mathrm{Fe}-\mathrm{Cr}-\mathrm{Al}$ alloys for attenuation of machine part vibrations. They showed that addition of small content of aluminium remarkably increased the damping capacity which was found to be reciprocally proportional to the coercive force and thereby to magnetically soft state of samples. Ferguson [6] characterised Al and Mo containing ferritic alloys for naval ship silencing applications. The specific damping capacity measured using a resonant dwell technique was found to be more interesting at higher frequencies close to $1 \mathrm{kHz}$ as compared to other families of high damping alloys. Schneider et al.[7] using cantilever and resonant bar methods observed that the damping capacity was strongly dependent on the chemical composition and the residual stress of samples. Heat treatment improved the damping capacity up to one order of magnitude in alloys containing $12-14 \%$ chromium. In spite of successful attempts to detect the internal loss capability of ferritic steels, their possible industrial applications require still an improvement of their damping capacity. For this purpose, a series of experiments were conducted to evaluate effects of alloying and annealing on the damping capacity of iron$16 \%$ chromium base alloys. A particular attempt was made to verify the damping behaviour when they are used as a coating of 2-3 mm thickness deposited on the steel substrates. The objective of the present work is to characterise the damping capacity in relation with the crystalline and magnetic microstructure as observed using the magneto-optical Kerr effect. Experiments are focused in particular on the damping behaviour at higher frequencies and elevated amplitudes. 


\section{EXPERIMENT}

The tested materials were $\mathrm{Fe}-16 \% \mathrm{Cr}$ (wt.) alloys containing ( 0 to $6 \%) \mathrm{Al}$ and $(0$ to $4 \%) \mathrm{Mo}$. The alloys were prepared from raw materials of $99.9 \%$ purity melted in a high frequency induction furnace working under high vacuum. Two of these alloys $(\mathrm{Fe}-16 \% \mathrm{Cr}$ and $\mathrm{Fe}-16 \% \mathrm{Cr}-2 \% \mathrm{Al}$ ) were tested also as a thick coating deposited onto steel substrates using a thermal spraying process [8]. The damping capacity of the flat beam samples was measured over a wide range of frequencies $(10 \mathrm{~Hz}$ to $1 \mathrm{kHz})$ and deformations $\left(\varepsilon=10^{-5}\right.$ to $10^{-3}$ ) using a cantilever device. This experimental method allows to determine the loss factor of a beam by measuring the response to excitation at modal frequencies. The resonance peak is first recorded monitoring vibration frequency at a given driving force, and then using the half power point at the resonance the damping capacity was determined. To obtain various resonance frequencies, the beam width and grip length were maintained fixed, but the vibrating length and thickness were left as variables. In addition, multiple resonance frequencies corresponding to normal modes of vibrating sample can be used to cover a large spectrum of experimental conditions. The vibration signals were measured using a laser vibrometer instead of an accelerometer or a strain gauge to avoid any alteration of sample response during experiments. For more accurate determination of $Q^{-1}$, the resonant peak was recorded by focusing the measurements to a narrow frequency band around the resonance and the beam values were taken at every $0.1 \mathrm{~Hz}$. Two examples of the resonance peak obtained for an annealed $\mathrm{Fe}-16 \% \mathrm{Cr}-2 \% \mathrm{Al}$ sample under different driving forces are shown in Fig.1. Diagrams of Fig.1 a correspond to the initial state of sample without application of an external magnetic field. One can note that the resonance peak first shifts towards lower frequencies with increasing driving force, and then beyond a given limit the tendency inverses and peak moves again towards higher frequencies. This behaviour is related to strong strain amplitude dependency of the non linear hysteresis damping capacity in ferromagnetic materials. On the contrary, when this sample is excited under a magnetic field beyond the saturation magnetization, the resonance peaks remain always symmetrical and do not show any shift as can be observed from diagrams of Fig.1b. In such a case, the magnetic moments are supposed to be aligned with the magnetic field and the irreversible movement of domain walls are restricted. Consequently, the damping capacity have to be attributed to other mechanisms than the domain dynamics, for example dislocations dynamic. In general, values of $Q^{-1}$ under saturation magnetization was found to reach 15 to $20 \%$ of the total damping capacity of the $\mathrm{Fe}$-Cr alloys.
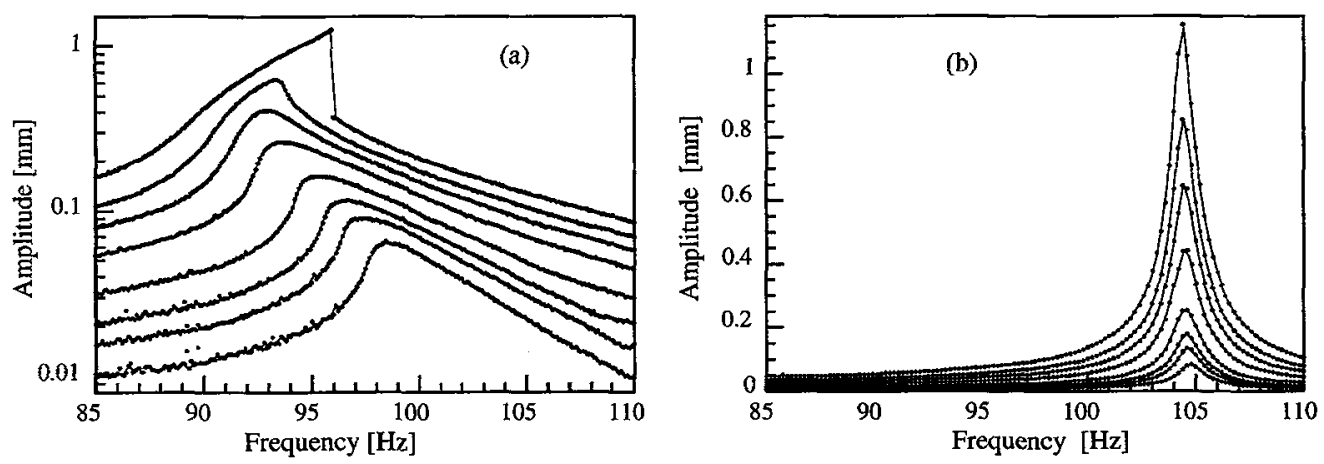

Figure 1: Resonance peaks recorded under different driving force in $\mathrm{Fe}-16 \mathrm{Cr}-2 \mathrm{Al}$. a) without application of magnetic field, peaks shift towards lower frequencies. b) under saturated magnetization the resonance peaks remain symmetrical.

\section{RESULTS}

\subsection{Damping capacity versus strain amplitude}

Typical examples of the damping capacity versus strain amplitude are shown in Fig. 2 for Fe-16Cr-1Al and Fe-16Cr-2Mo alloys. In both cases, as-received samples exhibit very low $Q^{-1}$ which remains practically independent of the vibration amplitude. Annealing of samples improve their damping capacity several times which becomes strongly strain dependant . In general, $Q^{-1}$ increases first rapidly with strain amplitude to a maximum around strain $\varepsilon=10^{-4}$, and then decreases relatively slowly to its initial values. Such a convex feature of the $Q^{-1}$ curve is peculiar to the ferromagnetic materials and has also been observed using resonant bar or torsion pendulum method [3,4]. The convexity of curves may be somehow influenced by testing methods due to differences in sample stressing or vibrational mode which implies the damping mechanisms to operate differently along the samples. The hysteresis damping is believed to increase almost linearly with the stress amplitude following a Rayleigh law for small stresses and when this limit is passed, it decreases gradually with the square of the stress [2]. Damping behaviour of thermally sprayed coatings was found very similar to those of cast alloys having the same chemical composition [8]. The main difference between 
them lies in the annealing conditions to obtain the maximum damping capacity $\left(Q_{\max }^{-1}\right)$. In general, thermally sprayed coatings exhibit finer microstructures and higher internal stresses than cast alloy samples and consequently, a higher annealing temperature or a longer annealing time is required to get the same magnitude of the damping capacity as cast alloys.
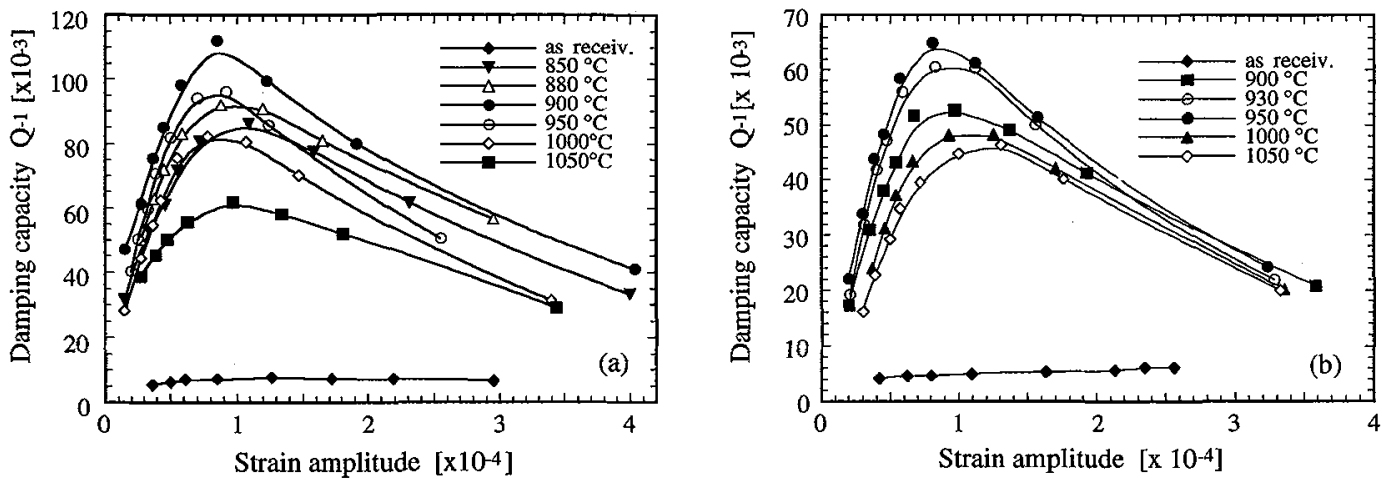

Figure 2: Variation of the damping capacity versus strain amplitude in as-received and annealed samples measured at $405 \mathrm{~Hz}$. a) Fe-16Cr-1A1. h) Fe-16Cr-2Mo

\subsection{Effect of heat treatment}

As-received cast samples and coatings have usually not appropriate microstructures to provide a high damping capacity and thus a particular annealing is always necessary to restore their $Q_{\max }^{-1}$. However, excessive maintaining under higher temperature or longer duration destroys the loss capability of ferritic alloys (Fig.3a). According to these diagrams the maximum value of $Q^{-1}$ for cast $\mathrm{Fe}-16 \mathrm{Cr}-1 \mathrm{Al}$ and $\mathrm{Fe}-16 \mathrm{Cr}$ 2Mo samples was obtained after maintaining $1 \mathrm{~h} / 900^{\circ} \mathrm{C}$ and $1 \mathrm{~h} / 950^{\circ} \mathrm{C}$, respectively. Higher temperatures decreased it significantly to approach damping values of as-received samples. Thermally sprayed coatings behave as cast alloys but due to their elevated residual stress require higher temperatures, around 1100$1200^{\circ} \mathrm{C}$, to restore their maximum damping capacity. Similar effects have also been encountered regarding the annealing duration. Consequently, each alloy with a given chemical composition can be optimised for its maximum damping capacity according to heat treatment conditions. Such a reduction of $Q_{\max }^{-1}$ with further annealing has also been observed in other works dealing with the loss capability of ferritic $\mathrm{Fe}-\mathrm{Cr}$ base alloys [4] and has been attributed to precipitation of $\sigma$ phase and decomposition of $\alpha$ phase. Based on these observations the optimised damping capacity of several alloys was investigated and the results are reported in Fig. $3 \mathrm{~b}$. As can be detected from this diagram $\mathrm{Al}$ containing alloys seem to show relatively higher $Q_{\max }^{-1}$ than Mo containing alloys, and also coatings exhibit lower damping capacity as compared to cast alloys.
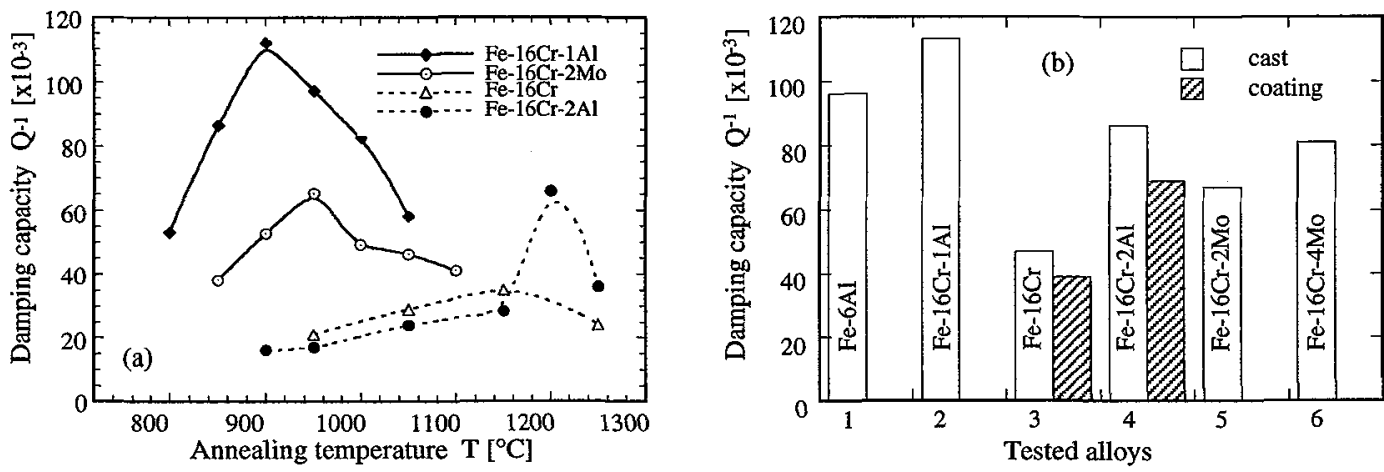

Figure 3: Effect of annealing on the damping capacity. a) further annealing decreases hysteresis damping $Q^{-1}$, solid line is cast alloy and dashed line is coating, b) Comparison of the maximum damping capacity $Q_{\max }^{-1}$ of various alloys.

\section{3 - Magnetic domain structures}

The hysteresis loss is believed to arise from dynamics of domain walls caused by rotation or movement of $90^{\circ}$ domain rather than $180^{\circ}[2,3]$. To study relationship between domain structures and damping capacity, and to distinguish behaviour of different domain types, the polished samples were observed using the magneto-optical Kerr effect. An external tensile stress as well as a variable magnetic field was Loss applied 
to the specimens. In a previous study the influence of annealing on the structural modification of domains and their mobility in iron-chromium alloys was investigated [8]. Here, examples of wall displacement occurred under different applied magnetic field and tensile stress are presented in Fig.3(a-c) and 3(d-k), respectively. The micrographs correspond to the same area of an annealed sample which includes 3 grains indicated $\mathrm{A}, \mathrm{B}$ and $\mathrm{C}$. Increasing the magnetic field along $\mathrm{S}$ direction displaces domain walls particularly in grain A from left to right (see $\mathrm{a}, \mathrm{b}$ ).The motion has been achieved in Fig.3c, where domain contrast has become uniform. In contrast, when this sample is subjected to an applied stress corresponding to Rayliegh region no significant change has been occurred in grain A, but grain B leads to some modifications indicated by arrow (micrographs e, f). Further deformation of the sample to a strain beyond the Rayliegh region results in remarkable changes in domain configuration, particularly, in grains B and C but not in A (see g-k). This difference in domain displacement observed under magnetic field and stress field can be attributed to the fact that under an uniaxial tensile stress the local strains within the sample does not remain uniderctional and due to grains compatibility other components may be activated which arise more complicated wall displacement.

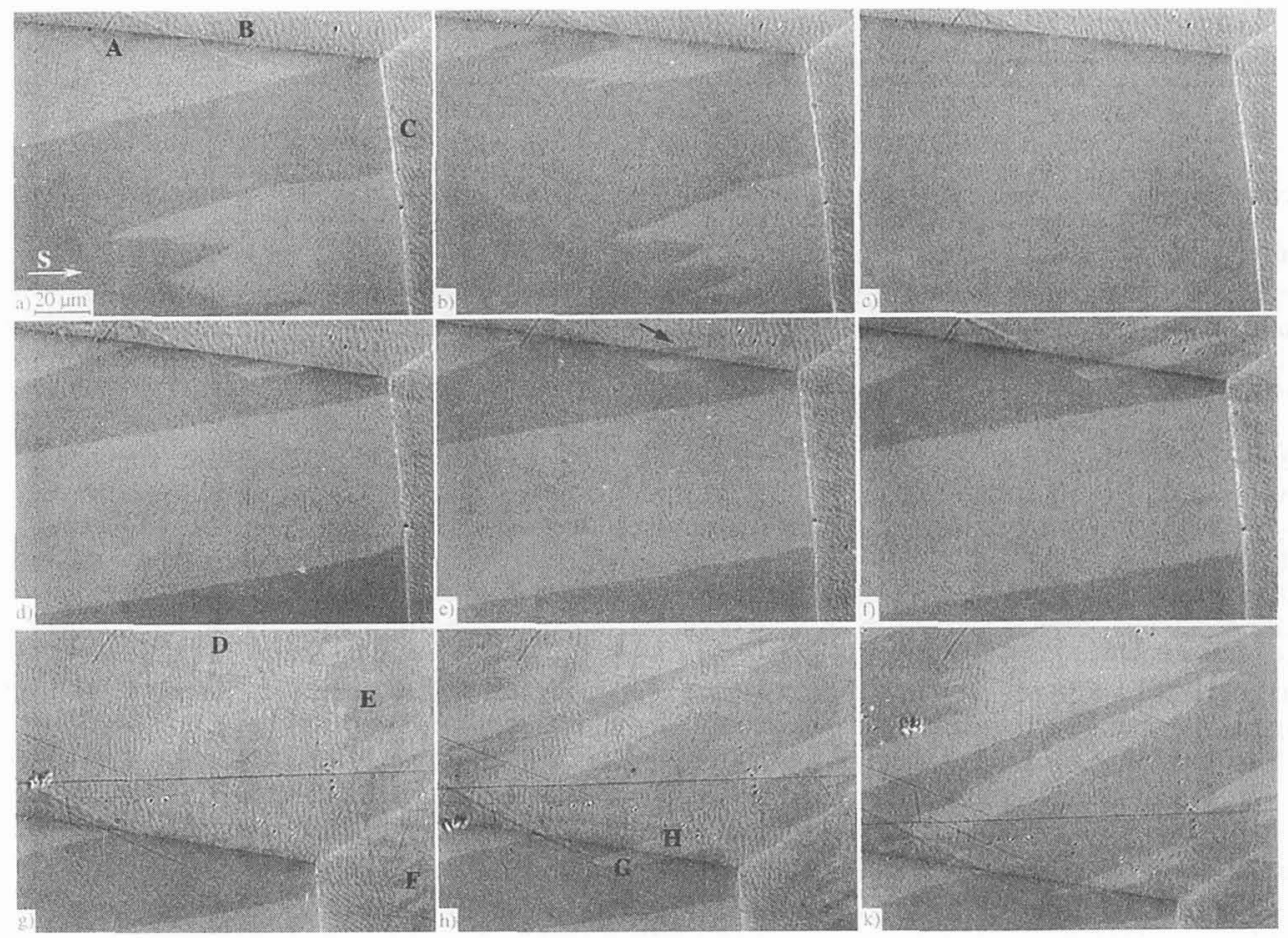

Figure 4: Displacement of magnetic domains in an annealed Fe-16\% Cr-2\%Al sample. a - c) effect of magnetic field, $\mathrm{d}$ - f) effect of low strain within the Rayleigh region), $\mathrm{g}-\mathrm{k}$ ) effect of high strain beyond the Rayleigh region.

Acknowledgements: The authors wish to thank G. Barbezat and A. Salito from Sulzer Metco in Wohlen for providing the VPS coatings. The Swiss Priority Program on Materials (PPM) is acknowledged for financial support of the project.

\section{REFERENCES}

[1] Bozorth R. M., in Ferromagnetism, Van Nostrand Co., Princeton, (1951).

[2] Cochardt A. W., J. Appl. Mech. 20 (1953) 196-200.

[3] Smith G. W. and Birchak J. R., J. Appl. Phys., 40(13) (1969) 5174-5178.

[4] Masumoto H., S. Sawaya and Hinai M., Trans JIM, 20 (1979) 409-413.

[5] Amano K., Sahashi M., Tokoro H. and Nakagawa M., Proc. 6th Int. Conf. on Internal Friction and Ultrasonic Attenuation in Solids, July 4-7, 1977, Tokyo, edited by R.R. Hasiguti and N. Mikoshika, University of Tokyo Press, 763-768 (1977).

[6] Ferguson D. B.,"Characterization of high damping Fe-Cr-Mo and $\mathrm{Fe}-\mathrm{Cr}-\mathrm{Al}$ alloys for naval ships applications", M.S. Thesis, Naval Postgraduate School, Monterey, California (1988).

[7] Schneider W., Schrey P., Hausch G., Török E., Journal de Physique, C5, Nº10(42) (1981) 635-639.

[8] Karimi A., Giauque P. H., Martin J. L., J. Appl. Phys. 79 (3) (1996) 1670-1677. 